\title{
Agentes electorales y reformistas: La acción política de la policía bonaerense en las variaciones del conservadurismo, 1902-1914
}

DOI: $10.15175 / 1984-2503-202113307$

\section{Pedro Berardi*}

\section{Resumen}

El artículo analiza a la institución policial en tanto actor protagónico de la política del período 1902-1914 en la provincia de Buenos Aires. Si bien el "orden conservador" (1880-1916) se encuentra en revisión historiográfica en Argentina, la policía no ha sido objeto de un examen atento a sus intervenciones y representaciones en dicho contexto. En diálogo con esta producción, se revelan variantes acuerdos y tensiones en la intervención policial que fueron constitutivas de la política, a la vez que definitorias de la propia configuración institucional. Por ende, se ponen en discusión visiones monolíticas y de maleabilidad de la policía, ya que se argumenta que más allá de las fuertes correspondencias entre ésta y las autoridades provinciales/locales, existieron divergencias y la necesidad constante de negociar las lealtades. Al tiempo que la policía no fue una institución heterónoma, sino que se apropió de las requisitorias de las autoridades políticas desde una clave permeada por las aspiraciones y las especificidades que les otorgaban sus funciones.

Palabras claves: Policía; Buenos Aires (Argentina); politización; orden conservador.

Agentes eleitorais e reformistas: A ação política da polícia de Buenos Aires nas variações do conservadorismo, entre 1902 e 1914

\section{Resumo}

O artigo analisa a instituição policial enquanto protagonista política na província de Buenos Aires no período 1902-1914. Embora a "ordem conservadora" (1880-1916) seja objeto de revisão historiográfica na Argentina, a polícia não tem sido submetida a um exame cuidadoso quanto às suas intervenções e representações no referido contexto. Em diálogo com essa produção, revelam-se distintos acordos e tensões, a um só tempo constituintes da política de intervenção policial e definidores da própria configuração institucional. Por conseguinte, colocam-se em discussão visões monolíticas e de flexibilidade da polícia, tendo em vista o argumento segundo o qual, para além da forte correspondência entre a polícia e as autoridades provinciais / locais, existiam divergências e a necessidade constante de negociação das lealdades. Ao mesmo tempo, a polícia, que não era uma instituição heterônoma, apropriava-se das demandas das autoridades políticas graças a uma chave codificada pelas aspirações e especificidades que lhes davam as suas funções.

Palavras-chave: Polícia; Buenos Aires (Argentina); politização; ordem conservadora.

* Profesor da Universidad de San Andres, Argentina/ Departamento de Humanidades - Profesor da Universidad Torcuato Di Tella, Argentina / Departamento de Estudios Históricos y Sociales. Doctor en Historia, Universidad de San Andrés. E-mail: pedroaberardi@hotmail.com. (1) https://orcid.org/0000-0002-9387-3067 
Passagens: Revista Internacional de História Política e Cultura Jurídica

Rio de Janeiro: vol. 13, n 3, setembro-dezembro, 2021, p. 530-550.

Agents of election and reform: Political activities of the Buenos Aires police in the various strands of Conservatism, 1902-1914

\begin{abstract}
This article analyzes the police institution as a main player in the politics of the period of 1902-1914 in the province of Buenos Aires. Although the "conservative order" (1880-1916) is currently under historiographical review in Argentina, the police has not come under scrutiny for its interventions and representations in such a context. In dialogue with this task are varying agreements and tensions in police intervention both constituting policy and defining the institutional configuration itself. The police's monolithic and malleable visions are therefore discussed, revealing that beyond the strong links between the police and the provincial/local authorities were significant differences and a constant need to negotiate loyalties. The police was thus not a heteronomous institution, instead appropriating the requisitions of the political authorities from a standpoint permeated by the aspirations and specifics that conferred its roles.
\end{abstract}

Keywords: Police; Buenos Aires (Argentina); politicization; conservative order.

Agents électoraux et réformistes : L'action politique de la police de Buenos Aires au sein des variations du conservatisme, 1902-1914

\title{
Résumé
}

Cet article analyse l'institution policière en tant qu'acteur politiquement engagé de la période 1902-1914 dans la province de Buenos Aires. Bien que l'« ordre conservateur » (1880-1916) se trouve déjà dans un processus de révision historiographique en Argentine, les interventions et représentations de la police dans ce contexte n'ont pas encore fait l'objet d'un examen attentif. En dialogue avec ces travaux de révision historiographique, nous avons mis en lumière différents accords et tensions qui s'avèrent autant constitutifs de la politique d'intervention policière que de la propre configuration institutionnelle. Cela permet donc de mettre en débat des visions monolithiques et la malléabilité de la police, étant donné qu'au-delà des liens forts qui la lie aux autorités provinciales/locales, on a pu constater des divergences et la nécessité constante de négociation des loyautés. En même temps, la police n'était pas une institution hétéronome, mais s'appropriait plutôt les demandes des autorités politiques à partir d'une approche codifiée par les aspirations et les spécificités que leur octroyaient leurs fonctions.

Mots-clés : Police ; Buenos Aires (Argentine) ; politisation ; ordre conservateur.

选举监督者和改革的促进者一阿根廷首都布宜诺斯艾利斯的警察群体在保守主义运动中的政 治行动，1902-1914

摘要

文章分析了阿根廷布宜诺斯艾利斯省 1902 至 1914 年期间警察机构的政治参与。史学界近年来对阿根廷的

“保守秩序” (1880-1916 年) 有所重视，学者们对以往的观点有所修正，但尚未对警方在“保守秩序” 期间 的政治参与和政治干预行动进行仔细审查和表述。本文尝试讨论警察干预政治的行动，以及警察制度对其本身 职能的定义，这两者之间的协同性与紧张性。本文认为，警察制度在思想与行为上具有很强的可塑性，他们需 要协调省/市地方当局之间的政治分歧，并且经常需要协商自己的忠诚 (因为警察需要效忠于不同层级，代表不 同利益的政治当局)。我们认为，警察不是一个他律的机构，他们自己会有选择性地应对不同的政治当局的需 求。警察机构，是解读阿根廷政治体制的一把钥匙，他们的职业特殊性决定了他们的政治取向，他们的社会愿 望渗透了他们的政治行动。

关键词：警察；布宜诺斯艾利斯（阿根廷）；政治化；保守秩序。 


\section{Introducción}

Desde las últimas décadas, la policía constituye en Argentina un objeto de estudio específico gracias al desarrollo y a la convergencia de múltiples enfoques interdisciplinarios y tradiciones historiográficas, que han problematizado a su vez a las propias narrativas institucionales (entre otros, BARRY, 2018; GALEANO; KAMINSKY, 2011). En efecto, durante buena parte del siglo $\mathrm{XX}$, ante la recurrente necesidad de enaltecer los rasgos más heroicos de los actores policiales y su carácter pretendidamente autónomo, estas últimas construyeron visiones de acentuado cariz hagiográfico (en especial sobre el espacio bonaerense, BUCICH ESCOBAR, 1923). De esta forma, soslayaron las prácticas y las manifestaciones de sus integrantes, en torno a sus cuestiones como participación en los procesos políticos.

Este artículo analiza a la institución policial en tanto actor protagónico de la política del período 1902-1914 en la provincia de Buenos Aires. Si bien el "orden conservador" (1880-1916) se encuentra en proceso de revisión historiográfica, la policía no ha sido objeto de un examen atento a sus intervenciones y representaciones en dicho contexto. Así, proponemos un diálogo con los trabajos que revisitan los entramados de la política nacional y provincial del período. ${ }^{1}$ De acuerdo con estas miradas, el orden político no se sostuvo en plenos consensos entre las filas del Partido Autonomista Nacional. Se ha complejizado por ende la caracterización de una elite oligárquica que actuaba como un grupo cerrado y homogéneo, y que poseía a su vez la capacidad de controlar las estrategias de perpetuación en los cargos mediante la puesta en práctica de maquinarias electorales. Señalándose, por el contrario, posturas divergentes respecto del sistema republicano y las transformaciones socioeconómicas y un conjunto de reformas ensayadas para modificar las instancias de participación.

Aunque contamos con aportes sobre la interpelación de las fuerzas políticas a las redes de comisarios y subalternos (BARTOLUCCI; TARONCHER, 1994) y se ha mostrado la capacidad de movilización de los comisarios y su influencia en las instancias electorales (FERNÁNDEZ IRUSTA, 2009), resta mucho por ser explorado en relación a la policía. En particular, consideramos necesario problematizar el rol de subordinación de la institución y

${ }^{1}$ La obra de Botana (1977) ha trazado un significativo cuadro sobre el régimen político que actualmente ha sido enriquecido. Para un balance sobre estas líneas y síntesis bibliográficas y problemáticas del período remitimos a Romero (2008), Alonso (2010), Míguez (2012), Cucchi y Rojkind (2017). Acerca de la política en Buenos Aires, entre otros Hora (2001) y Palacio (2013). 
de control vertical ejercido por las diversas administraciones de signo conservador, presente en algunas de estas narrativas.

Consideramos que más allá de las fuertes correspondencias entre la policía y las autoridades provinciales/locales, se revelan divergencias y la necesidad constante de negociar las lealtades. Al tiempo que la policía no fue una institución heterónoma, sino que se apropió de las requisitorias de las autoridades políticas desde una clave permeada por las aspiraciones y las especificidades que les otorgaban sus funciones. Para dar cuenta de ello, hemos delineado una periodización que se desplaza de aquella basada en las sucesivas gestiones que los estudios de la propia institución propusieron (MUÑIZ; FORS; GAMBIER 1911; POLICÍA DE LA PROVINCIA DE BUENOS AIRES, 1981); para atender en cambio a las modulaciones y especificidades de la relación entre los actores policiales y la esfera política.

En otro artículo (BERARDI, 2019a) estudiamos las primeras dos coyunturas: 18801892 y 1892-1902. Inicialmente, se destacaron las convergencias entre las figuras del autonomismo provincial y la Jefatura en torno a la necesaria centralización, tras la federalización de Buenos Aires en 1880 y el incipiente proceso de formación estatal a la vez que de creación de la policía provincial. Entre otras cuestiones, en política ello supuso atenuar el faccionalismo mientras que, de cara a la organización policial implicó la definición de un organigrama piramidal con eje en la Jefatura. Por el contrario, revelamos que entre 1892 y 1902 la impugnación al sistema político fue cada vez mayor, sobre todo a raíz de los levantamientos armados radicales. Lo que desarticuló el entramado autonomista al tiempo que impactó en una policía cada vez más alejada de las autoridades que la administraban y más cercana a las figuras de poder locales.

En estas páginas ponemos la lente en el momento: 1902-1914, a la vez subdividido en dos. Primero, se abordan los enclaves territoriales de la policía tomando como marco la gestión inicial de Marcelino Ugarte entre 1902 y 1906, donde se advierte una construcción más negociada del orden político que en la etapa previa. Para ello se detallan los sucesos ocurridos en Carmen de Patagones, -ubicada al extremo sur bonaerense y por lo tanto espacio significativo para atender a las articulaciones institucionales lejos de los centros políticos- al calor de los preparativos de las elecciones presidenciales y municipales, en tanto caso testigo de dicho entramado. Especialmente, interesa la intervención del oficial Fabio Dozo en el juego electoral local, en la medida en que matiza las nociones sobre un orden político hegemónico, como también de una policía jerarquizada y sin capacidades de 
negociación. Luego, se observa la manera en que la institución recibió y experimentó las reformas electorales nacionales y provinciales entre 1906 y 1913. Por entonces, triunfó en Buenos Aires la línea opositora al ugartismo dentro de los Partidos Unidos y con la llegada de Figueroa Alcorta a la presidencia, un segmento de la elite política impulsó un proceso reformista que fue acompañado tanto por el elenco de gobernadores saenzpeñistas, como así también por las gestiones policiales.

\section{Marcelino Ugarte y Luis María Doyhenard en la (re)centralización política y policial, 1902-1906}

La asunción de Marcelino Ugarte como gobernador de Buenos Aires en mayo de 1902, con un sentido más atento hacia la reforma política, abrió una nueva etapa en la administración policial. ${ }^{2}$ Gracias al acuerdo en los Partidos Unidos pudo ampliar los recursos destinados a los servicios de seguridad y dio una mayor jerarquización a la Jefatura. Designó además nuevos funcionarios: en la Jefatura a Mateo Ruíz Díaz, mientras que Luis María Doyhenard fue nombrado comisario de órdenes. ${ }^{3}$

El accionar de ambos y en particular de Doyhenard en la exitosa represión del cuatrerismo, comenzó a cambiar las expectativas negativas sobre el cuerpo que habían signado la gobernación de Bernardo de Irigoyen entre 1898 y 1902, cuando la actividad policial fue cuestionada por su injerencia en las rivalidades políticas (BERARDI, 2019a). La presencia de la Jefatura en las localidades a los fines de organizar las comisarías y promover en ellas a "los hombres de posición independiente" y la disminución del abigeato, fueron leídos entonces como un signo manifiesto del reordenamiento territorial e institucional desplegado por la policía. ${ }^{4}$

A los pocos meses, en agosto de 1902, Doyhenard sucedió a Díaz en la Jefatura. Desde entonces continuó con el acelerado proyecto de modernización y profesionalización de la fuerza. El mismo no era nuevo, ya que desde 1880 integraba la agenda policial, por

\footnotetext{
2 Ugarte asumió de forma convulsionada. Debió afrontar las hostilidades de fracciones que integraban los Partidos Unidos -coalición conformada por figuras del radicalismo acuerdista y del autonomismo- que había impulsado su postulación. Se vio también limitado en la Legislatura por los modernistas opositores. Sobre esta coyuntura, Tato (2005).

${ }^{3}$ Dentro del complejo entramado del cuerpo policial se definieron, desde sus momentos iniciales en 1880 , una multiplicidad de reparticiones que se fueron concentrando en las dependencias de la Jefatura. Supeditadas a las actividades administrativas, prevención urbana, aprovisionamiento y a la producción y clasificación de información. La Comisaría de Órdenes —que en 1903 sería reemplazada por la Inspección General-continuaba en jerarquía al jefe de policía y tenía potestad sobre el resto de los destacamentos que componían la institución.

${ }^{4}$ Por ejemplo, se destacaron visiones positivas de diversos actores en La Nueva Provincia, Bahía Blanca, $13 / 5 / 1902$ y $6 / 7 / 1902$.
} 
lo que Doyhenard logró darle continuidad y consolidarlo. Esta nueva etapa fue celebrada también por la prensa institucional. La Revista de Policía enfatizaba el lugar social y la modernización recuperadas gracias a la gestión de Ugarte. Un punto de inflexión en este sentido era que el gobernador hacía frente al "tutelaje que ha venido ejerciendo sobre la policía el caudillismo porteño". 5

De hecho, Doyhenard articuló su programa sirviéndose de los mecanismos de centralización de Ugarte para disciplinar y reagrupar a las autoridades comunales (BÉJAR, 2005, p. 26-27). Su intención era restituir la centralización perdida en el decenio anterior, por lo que apuntó a reconstruir un tejido político estructurado sobre el centro provincial -la ciudad de La Plata-, para desplazar la preeminencia de intendentes, comisionados y otros intermediarios locales en las maquinarias electorales.

Los puntos de conexión con las formas de construir poder territorial de Ugarte resultan por ende un elemento fundamental para comprender la gestión y dinámica institucional de la policía en el período. Al respecto, una de las primeras medidas de Doyhenard fue redireccionar las conexiones entre el Departamento platense y las distintas reparticiones. ${ }^{6}$ Y esto era funcional a la creación del Escuadrón de Seguridad y de los cuerpos de Gendarmería Volante y de Islas también afines a la configuración de un territorio centralizado y del disciplinamiento junto a la especialización del servicio (BERARDI, 2018).

El poder de Ugarte se cimentaba sobre dichos entramados. Además de la proximidad política -dado que Doyhenard había sido diputado provincial por el Partido Autonomista Nacional entre 1891-1893 y 1898-1900-, la función que el jefe desplegó era potencialmente significativa para realinear sus apoyos políticos. La siguiente imagen de Caras y Caretas enseña esa correspondencia. Con el característico tono satírico de esta revista nacional de tirada masiva, el epígrafe alude a la necesidad del gobernador de disponer de la experticia y la eficacia policial en la punición de determinados delitos para conformar un cuerpo de funcionarios que le sea adepto: "D: -Señor, ya encontré todos los cuatreros que se buscaban. U: -Bueno. Pues, ahora, á ver si me encuentra ministros."

${ }^{5}$ BN, Revista de Policía (en adelante RP), N² 24, La Plata, 15/6/1902.

${ }^{6}$ AGN, Sala VII, Colecciones Particulares, Fondo Luis María Doyhenard (en adelante FD), L.1-fs-818-20. 


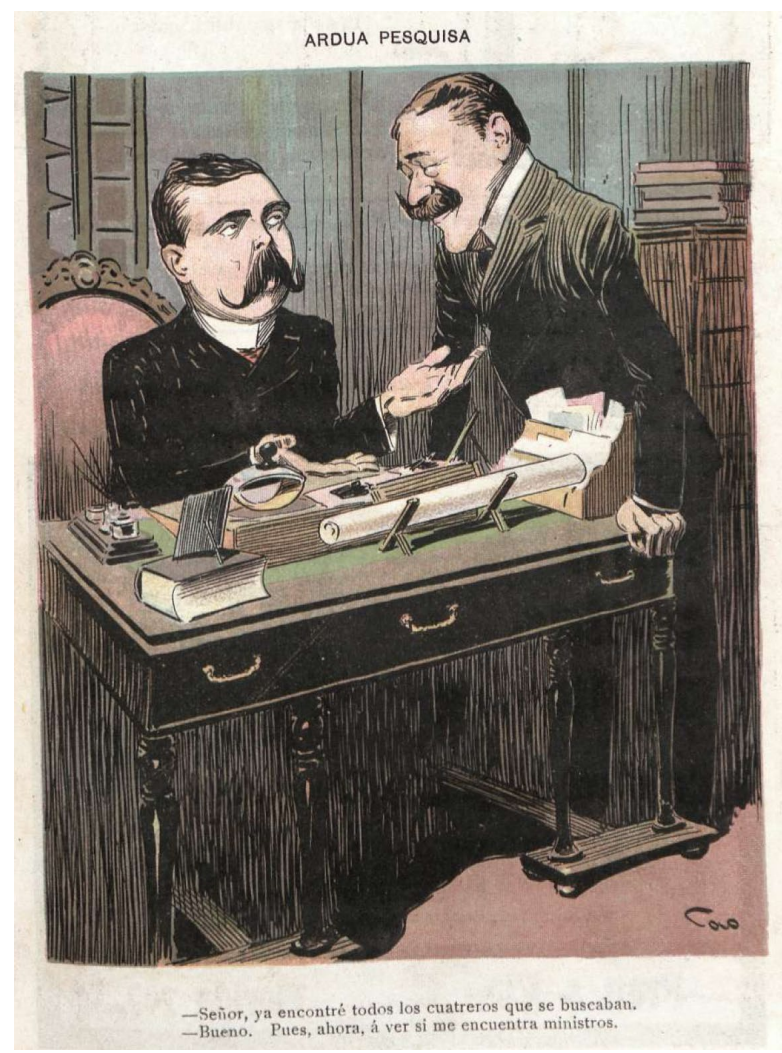

Fuente: BIBLIOTECA NACIONAL DE ESPAÑA. "Ardua pesquisa”, Caras y Caretas, n. 201, p. 1, 9 jul. 1902.

Pese a las dificultades de Ugarte en la conformación de un gabinete propio, luego de la intervención nacional la correlación de fuerzas al interior de la provincia se le tornó más favorable. ${ }^{7}$ En el marco de la apertura a la carrera presidencial para 1904 , Julio A. Roca le confirió su respaldo al objeto de debilitar a los Modernistas, liderados por Pellegrini. Ello le posibilitó al flamante gobernador obtener el apoyo de figuras hasta entonces adversas. No obstante, su interacción con la Jefatura de policía no fue unilineal, como tampoco lo fue para Doyhenard reconstituir, sobre la base de las formas políticas del conservadurismo, una organización piramidal cimentada en las adhesiones de comisarios y agentes.

En determinadas experiencias locales, el jefe de policía necesitó negociar mecanismos de integración y obediencia que fueron en discordancia con la idea de configurar un cuerpo policial centralizado y subordinado. Asimismo, concitar la adhesión de la Jefatura implicaba para los subalternos capitalizar los respaldos políticos al interior de las tramas electorales de las comunidades en las que operaban.

${ }^{7}$ En una puja por la designación de funcionarios, Ugarte se vio limitado en el control de la Legislatura provincial, que en composición era mayormente opositora. Es por ello que, a mediados de 1903, solicitó al Ejecutivo nacional la intervención federal para lograr se aprobasen los resultados de los comicios que lo habían consagrado como mandatario bonaerense. 
En este sentido, la experiencia de Patagones cristaliza las tensiones y solidaridades que se fueron tejiendo entre la policía, los grupos de notables que ocupaban cargos de poder y las autoridades provinciales, en la coyuntura de los acuerdos intraelitarios de cara a las elecciones presidenciales y municipales. A partir de un enfoque tributario de la escala microanalítica, mostraremos cómo se fueron redefiniendo los términos de la arquitectura política y policial territorial durante la primera gestión de Ugarte. En este marco, damos cuenta de otra modalidad de intervención política de la policía, en tanto artífice de la construcción de fuerzas partidarias.

\section{El caso de Patagones}

Emplazada en el extremo sur de la provincia, Patagones fue adquiriendo fisonomía urbana después de las avanzadas militares sobre la Patagonia. El control sobre tierras fiscales y el área de salinas que conformaba una meseta adyacente a Bahía Blanca, posibilitó la constitución de un grupo de familias que se distribuyeron tempranamente los escaños de poder. En los albores del siglo XX, muchas de ellas apoyaron la llegada de Ugarte, por su promesa de sanear las crecidas de ríos que afectaban la economía.

No obstante, esta adhesión no fue homogénea dentro del arco político conservador de Patagones. La prensa local cristalizó esas fragmentaciones y colocó a la policía como uno de los principales objetos de diatriba. El diario La Unión tuvo un abierto apoyo hacia la administración de los Partidos Unidos. Centro de sus denuncias fue el comisario Blassetti, que amparado por el intendente oficialista Antonio Barbieri, permitía la comercialización de ovinos y vacunos contramarcados. ${ }^{8}$ En consonancia con la idea de Doyhenard de "higienizar" la repartición, Blassetti fue exonerado. En su reemplazo fue nombrado Fabio Dozo, quien desde 1880 era sub-comisario en Bahía Blanca. Sus primeras intervenciones fueron bien recibidas por la prensa institucional, local y porteña por su rigurosidad en el esclarecimiento de un asesinato y su experticia en la campaña rural. ${ }^{9}$ Sin embargo, su actividad política concitó rechazos y reavivó la confrontación comunal.

Esta dimensión nos permite observar en qué sentido su búsqueda de lealtades distanció coyunturalmente al gobernador de la gestión de Doyhenard. A comienzos de 1904, el periódico La Nueva Era fue refundado por Mario Matteucci para apoyar la

${ }^{9}$ La Nueva Provincia, 29 agosto1902; RP, n. 10, 15 nov.1902. 
candidatura de Marco Avellaneda para secundar a Manuel Quintana -con el respaldo del mandatario Roca- en la fórmula presidencial. ${ }^{10}$ Desde sus páginas, impulsó entonces la conformación de la agrupación Unión Popular. Por su parte, el comisario Dozo inició trabajos para la constitución del comité Fomento de Patagones. ${ }^{11}$ Este consistía en una coalición que nucleaba al ugartismo disidente al intendente Barbieri junto al Círculo de Obreros Católicos.

A pesar de la carga de denuncia del diario, es posible identificar en sus múltiples notas las prácticas políticas encarnadas por Dozo, sirviéndose de su pertenencia policial. Como indicamos, la política de tierras había consolidado una trama vecinal que aseguró carreras exitosas en la esfera económica a la par que en la administración pública. Estas aspiraciones no eran ajenas al comisario. Inició el hostigamiento de propietarios o posibles compradores para allanar su participación en el mercado de tierras. Además, presionó para debilitar la competencia electoral, poniendo en prisión a destacados opositores. ${ }^{12}$ Sin embargo, fue durante los comicios de noviembre de 1904, donde los respaldos y redes de Dozo fueron cruciales para mantener su posición de poder local. Al mismo tiempo, le permitieron negociar la continuidad en su cargo ante Doyhenard y evitar su posible exoneración.

En Patagones debían renovarse los cargos de consejeros escolares y concejales. En esta coyuntura marcada por el traspaso presidencial, la correlación de fuerzas local tornó dificultoso el triunfo de la agrupación liderada por el oficial. Ante la posibilidad efectiva de que Quintana -candidato sostenido por Unión Popular- asumiese la presidencia, y debido al apoyo del gobernador Ugarte, quien evitaba quedar excluido de la protección roquista, Dozo puso en marcha una serie de estrategias para inclinar los resultados a su favor. A efectos de incorporar sufragantes al padrón y amedrentar opositores, trajo a Patagones a convictos la cárcel de Sierra Chica y bandidos de los Territorios Nacionales. Simultáneamente, solicitó a la Jefatura ocho agentes para reforzar el control sobre los confines del área rural, pero que, de acuerdo con La Nueva Era, operaron en la campaña como fuerzas del comisario. ${ }^{13}$

El nombramiento de éstos nos permite conjeturar que Doyhenard respaldaba las operaciones de Dozo, y que al sostenerlo aseguraba el control sobre los disidentes políticos en un escenario muy distante a la capital provincial. Con ello, desde la Jefatura se buscaba

\footnotetext{
10 Sobre la candidatura de Quintana, Botana (1977).

${ }^{11}$ MHR, La Nueva Era, Patagones (en adelante LNE), 20 nov. 1904.

12 LNE, 6 nov. 1904.

${ }^{13}$ LNE, 23 oct. 1904.
} 
lograr la rearticulación territorial mediante redes con subalternos, por las que se podía orientar comunas distantes; proceso necesario tras la fragmentación de la década de 1890 (BERARDI, 2019a).

No obstante, esta relación tuvo visos más complejos, ya que no fue unidireccional ni para Doyhenard ni para Dozo, del mismo modo en que tensionó los vínculos de Doyhenard con Ugarte. Semanas antes de las elecciones, los miembros de Unión Popular solicitaron el respaldo del gobernador para que se nombrara a otro comisario. Para atemperar la confrontación y evitar descréditos, Ugarte designó a una figura destacada de los Partidos Unidos y de la confianza del intendente Barbieri -el senador provincial López Cabanillas-, para intervenir la comuna en calidad de comisionado. Simultáneamente, autorizó a un oficial de Bahía Blanca para hacerse cargo de la comisaría de Patagones. ${ }^{14} \mathrm{E}$ instó a Doyhenard a remitir a un inspector de policía, para que normalizara la situación en la repartición. ${ }^{15}$

Mientras tanto, Dozo requirió su baja de la policía y comenzó un recorrido por los establecimientos rurales de la región para buscar apoyos de cara a las elecciones. ${ }^{16}$ Con ello pretendía evadir que a solicitud del Juzgado de Primera Instancia fuese remitido a la capital -La Plata-, para ser procesado por su desempeño y su intervención en los negocios fiscales. Pero a su vez, como dejó traslucir en la correspondencia entablada con las mismas autoridades, era consciente de su labilidad en la institución y de lo nocivo que podía ser que la Jefatura transitara un proceso judicial. ${ }^{17}$

Cuando los acontecimientos de Patagones adquirieron notoriedad nacional, Doyhenard tenía aspiraciones de ser gobernador en el recambio de $1906 .{ }^{18}$ Aunque parecía allanada la continuidad de los Partidos Unidos por el abstencionismo opositor, se dio una competencia intrapartidaria que fue condicionando su estabilidad. Además de arriesgarse a perder el respaldo de Ugarte, los conflictos que se daban en las municipalidades por la carrera electoral sumaron densidad.

Esta experiencia resulta ilustrativa entonces de la tensión del proyecto que, con cierto éxito, había promovido la centralidad y la fortaleza del poder ejecutivo bonaerense y de la cúpula policial. Por ello, aunque a Doyhenard le fuera incómodo legitimar las acciones de Dozo, tal legitimación era necesaria ante a la posibilidad de que el triunfo de la fracción

\footnotetext{
${ }^{14}$ FD, L.3-fs.30-44,15 nov. 1904.

15 LNE, 13 nov. 1904.

16 LNE, 20 nov. 1904.

17 FD, L.3-fs.104-5, 22 oct. 1904.

18 LNE, 13 nov. 1904 y 3-4 dic. 1904.
} 
quintanista definiera el equilibrio de fuerzas hacia otros actores. Claro que, si bien desde La Plata se buscó modular la capacidad de acción de Dozo, esto no obstruyó que sus agentes se desempeñaran con cierta autonomía.

Un escueto recorrido sobre los sucesos del 27 de noviembre de 1904 revela correspondencia y subordinación, pero también lógicas autónomas entre la cúpula policial y sus subalternos. Para asegurar la efectividad del sufragio, la mesa del atrio parroquial fue presidida por el inspector de policía. Los votantes acudieron en grupos, según adscripciones, comenzando con uno de la Unión Popular. Cuando llegaron los electores de Fomento de Patagones, agentes comandados por Dozo ocasionaron la muerte del fiscal Fabio Farías. Después de sustraer las urnas, amenazaron las instalaciones del club opositor. Al tener conocimiento Ugarte, anuló las elecciones y ordenó una nueva intervención de la comuna y la remoción temporaria de sus autoridades. Mientras tanto, el inspector de policía Lavié impulsó una investigación y puso a Dozo a disposición de la justicia. ${ }^{19}$

Más allá del tinte de denuncia de la cobertura de La Nueva Era, podemos rastrear indicios del entramado intra policial. La redacción estimaba que Lavié pudiese atemperar la beligerancia policial hacia los miembros de Unión Popular y recordaba que la Ley Electoral y el Reglamento de Policía normaban la prescindencia policial en las elecciones. Si bien el inspector ordenó la detención de Dozo, el tratamiento que le brindó distó de la aplicación de penas que Matteucci y sus colaboradores anhelaban. Incluso, ante la llegada del juez del crimen, Lavié sostuvo que las pruebas eran insuficientes.

Dicha situación remite a la multiplicidad de lealtades que Dozo configuró. Por una parte, pese a su renuncia, el subcomisario Flores y otros oficiales continuaban reconociendo su preeminencia, aun ante Lavié. ${ }^{20}$ Junto a la filiación partidaria, ello también se explica porque Dozo habilitó a la tropa una serie de beneficios. Por ejemplo, dado que la exigüidad salarial era frecuente, Dozo admitía el sostenimiento del juego ilegal en locales urbanos y de la campaña. Por otro lado, culminadas las investigaciones Dozo fue detenido, pero a principios de 1906 fue reincorporado a su cargo por orden de la Jefatura.

Así, se vislumbran las reciprocidades entre el gobernador y el jefe de policía. Pero a su vez, son identificables los puntos de divergencia a partir de sus propios intereses. Doyhenard asumió el respaldo del comisario de Patagones, que era allí artífice de su propia línea política. Mientras que Ugarte, para mantener el apoyo de Roca y su primacía en la

${ }^{20}$ LNE, 4 dic. 1904. 
provincia, apeló a la consolidación de un orden político digitado desde La Plata, afirmándose en la fracción del Partido Autonomista Nacional que postuló a Manuel Quintana como presidente.

\section{El interregno reformista, 1906-1914}

El período iniciado con el gobierno de Quintana, y la sucesión del vicepresidente Alcorta tras su deceso en marzo de 1906, le imprimió un nuevo ritmo a la política provincial. La figura de Quintana, si bien sostenida por Roca y Ugarte, carecía de consenso a escala nacional (CASTRO, 2012, p.111-162). De acuerdo a las semblanzas de un testigo de la vida parlamentaria, se inició un abierto desafío a Ugarte. La Legislatura era vista por sus opositores como el ámbito en el que se reproducían mecanismos de control territorial a partir de las tracciones que ejercían los caudillos locales.

No obstante, el respaldo del jefe de policía Doyhenard desbarató la estrategia de clausurarla (CARRASCO, 1947, p. 82-83). Si bien la negociación de Ugarte atemperó la injerencia policial y posibilitó la reincorporación del grupo disidente al bando oficialista, el debilitamiento de la figura presidencial dinamizó, a través del recambio, transformaciones que impactarían en los mecanismos de legitimación ciudadana. La asunción de Figueroa Alcorta viabilizó las aspiraciones de las elites próximas al reformismo electoral propugnado por Roque Sáenz Peña (ZIMMERMANN, 1995). Una directa posición antiroquista, impulsada desde la presidencia, se direccionó a desmontar la arquitectura de poder que sustentaba a Ugarte en Buenos Aires.

El inicio de este ciclo de reformas, principalmente en el plano de los mecanismos electorales, que fue acompañado por los diversos gobernadores que lo sucedieron, impactó en la dinámica de los partidos. Del mismo modo en que tuvo implicancias en las formas en que la policía miraba a los sectores a cargo de su administración.

Con el ascenso de Ignacio Irigoyen, en mayo de 1906, se abrieron expectativas dentro de las fuerzas gubernamentales de la provincia, aun cuando su candidatura fuera digitada por Ugarte (BÉJAR, 2005, p. 28; HORA, 2013, p. 60). Para la prensa opositora, el poder en sombras que el exgobernador detentaba ahora desde su banca de diputado, era posible debido a la acción coactiva de los agentes supeditados en los atrios para impedir el libre ejercicio del sufragio. Así, la perdurabilidad de estas prácticas impedía la adaptación a los cambios políticos y Ugarte, para sus contrincantes, representaba un anquilosado autonomismo. Es por ello que, como señala Béjar (2005), la creación del Partido Conservador 
en 1908 constituyó una estrategia significativa. Por un lado, para definir una estructura partidaria de carácter moderno, que dio mayor unicidad y fluidez a la definición de candidaturas. Por otro lado, dado que permitió desplazar a los cívicos y a los autonomistas próximos a Roca que habían cimentado la coalición de los Partidos Unidos y por tanto desarticularla. En este sentido, ello ayudó al reemplazo notabiliar, cuyo corolario fue la marginación de Ugarte de la arena política por un breve lapso (BÉJAR, 2005, p. 29-31).

Sin embargo, la conducción del partido no contaba con la legitimidad y la fortaleza suficiente para disputarle su gravitación, al menos hasta comienzos de la década siguiente (TATO, 2005, p. 134). Si bien el gobernador Irigoyen asumió una postura ambigua al mantenerse próximo al exgobernador, se decantó inmediatamente por alinearse con la política de Alcorta. La rivalidad con su antecesor limitó sus respaldos, sobre todo porque no pudo disponer de las lealtades que Ugarte continuaba traccionando desde la Legislatura, por fuera de la órbita del Partido Conservador.

En este marco, la construcción de adhesiones alentadas por la intervención policial constituía uno de los apoyos más importantes de los que disponía el gobernador saliente, los cuales le servirían posteriormente para recuperar su preeminencia en la estructura del conservadurismo. Al respecto, la correspondencia enviada a Doyhenard por comisarios inspectores nos ofrece algunos indicios acerca de la permanencia de esas filiaciones en el cuerpo policial. En el marco de la reorganización en las reparticiones que la nueva Jefatura estaba llevando a cabo, ${ }^{21}$ se destaca por ejemplo el caso de un oficial buscaba evitar su desplazamiento de la dotación por lo que apelaba a la mediación de su antiguo jefe. ${ }^{22}$ En igual sentido, órganos de prensa deslegitimaban a la gestión de Irigoyen, centrando sus críticas en la obra de su jefe de policía. Para ello efectuaban un contraste con los éxitos que atribuían a Doyhenard y que relacionaban con el proyecto ugartista, sugiriendo la rivalidad que compartían ambos mandatarios. En particular, se enfatizaba la imposibilidad de las transformaciones políticas debido a que los poderes locales se veían nuevamente fortificados. ${ }^{23}$

El triunfo de José Inocencio Arias, en 1910, supuso la consolidación del Partido Conservador como una de las fuerzas más relevantes en el juego electoral. Ello generó condiciones en la provincia para la aplicación de las reformas que se dinamizarían en la administración de su sucesor Ezequiel de la Serna, a pesar de la conflictividad facciosa que

${ }^{21}$ El nuevo jefe intentó corregir el comportamiento de los empleados y lograr la transparencia electoral. Boletín de Policía de la Provincia de Buenos Aires, n 11, La Plata, 31 mayo 1906.

22 FD, L. 3-fs. 664-5.

${ }^{23}$ Por ejemplo, FD, L. 2-f. 331. 
agravaría su temprana muerte. ${ }^{24}$ Tras el ensayo de la ampliación democrática que supuso la Ley Sáenz Peña, se fraccionó el tejido partidario. Próximo a la propuesta de la Unión Nacional -fuerza que apoyaba a Sáenz Peña a nivel nacional-, el Partido Conservador Principista planteaba amoldar la provincia al ritmo de los cambios políticos. La estrategia serviría además para tratar de limitar el poder de Ugarte, quien nuevamente adquirió notoriedad ante la proximidad de los recambios gubernamentales, al punto de asumirse como la figura central de la fuerza que lo había desplazado.

Estas transformaciones indudablemente fueron permeando las concepciones de la cúpula policial en torno a las prácticas políticas. Las jefaturas entre 1910 y 1914 estuvieron atravesadas por las ideas reformistas que postularon las sucesivas administraciones bonaerenses. ${ }^{25}$ En este sentido, promovieron una batería de disposiciones a efectos de ordenar y controlar las instancias del sufragio en consonancia con las leyes sancionadas.

Lograr la transparencia electoral constituía una de las principales aspiraciones mediante las que se buscaba recomponer la legitimidad de la fuerza. Ello se cristaliza en la ordenanza que el jefe Juan Taquini remitió telegráficamente a todos los comisarios, en el marco de los comicios practicados tras la sanción de la Ley Sáenz Peña en 1912, donde se mostró preocupado por conquistar "el aplauso público" para que la institución pudiera "ostentar uno de los galardones de más tono y orgullo". ${ }^{26}$ Asimismo, para evitar que sufragase el personal de diversas jerarquías y secciones, se procedió a que la oficialidad les retirase sus libretas de enrolamiento, considerando que la nueva ley preveía el empadronamiento a través del registro militar. Ello debía ser supervisado en las mismas comisarías por los representantes de las agrupaciones que participaban del comicio.

Igualmente, los requerimientos que exigía la ampliación del sufragio se correspondieron con el establecimiento de instancias educativas destinadas a los agentes. La buena formación y la correcta instrucción debían visibilizarse entonces en el acto comicial. Las pretensiones de una tropa más alfabetizada respondían así a la adopción de la nueva legislación, alentando la presencia de vigilantes que pudieran transmitir la pedagogía cívica. Sobre todo, porque además de supervisarlo, los sargentos y agentes

${ }^{24}$ En septiembre de 1912 Arias transfirió la gobernación a su vice De la Serna, quien falleció a los pocos meses. Fue sucedido interinamente por el presidente del Senado, mientras que el gobernador electo, Ortíz de Rosas, también moriría en septiembre de 1913 (HORA, 2013, p. 60-63).

25 Taquini fue designado en mayo de 1910 por Arias, hasta septiembre de 1912. Fue sucedido de manera interina por Chaumeil, a quien De la Serna confirmó en el cargo hasta septiembre de 1913, para ser reemplazado por Videla Dorna (POLICÍA DE LA PROVINCIA DE BUENOS AIRES, 1981, p. 294-295).

${ }^{26}$ POLICÍA DE LA PROVINCIA DE BUENOS AIRES, Memoria Anual correspondiente al ejercicio 1911-1912, 1912 (en adelante Memoria), p. 570-571. En adelante citas extraídas de aquí. 
estaban a cargo de transmitir o enmendar la información que los votantes disponían sobre las normas o las instrucciones para ejercer el voto. Como lo estipulaba la ley, el comisario debía disponer a los vigilantes con "mejores aptitudes y muy especialmente los egresados de la 'Escuela de clases' para que actúen bajo las órdenes del presidente de mesa".

Esta pedagogía cívica se complementó con otras funciones que el cuerpo policial fue incorporando en pos de regular la participación política. Ello le confirió una discrecionalidad que le posibilitó ordenar e intervenir en las formas que debían asumir las manifestaciones públicas, como así también la dinámica de los partidos. Junto a otras operaciones como la articulación territorial por la creación de divisiones y el uso de tecnologías como el telégrafo (BERARDI, 2019b), la aplicación de esas normativas colocaba a los comisarios en una situación de mediación entre las distintas fuerzas.

De manera tal que, en los días previos a una jornada electoral, los representantes partidarios debían acudir a los destacamentos para confirmar sus listas y definir el orden en que sufragarían, mientras que el oficial estipulaba la ubicación y el número de mesas, las distancias que tenían que mantener los grupos electores y la pertinencia de los fiscales. ${ }^{27}$ En igual sentido, a efectos de realizar reuniones en ámbitos públicos las agrupaciones debían solicitar la autorización policial y someterse a la estricta vigilancia del personal de facción.

Según ha planteado Roy Hora (2013, p. 63), tras la sanción de la Ley Sáenz Peña proliferaron los actos proselitistas por fuera de los grandes centros urbanos, por lo que las plazas y las calles de múltiples ciudades comenzaron a ser escenario de la concentración y la propaganda partidaria. Por lo tanto, esas solicitudes les otorgaban a los uniformados una capacidad de control y fijación de los recorridos por la que podían contener los usos del espacio y un lugar privilegiado para recabar información sobre los asistentes y los discursos proferidos.

En tal sentido, diversos telegramas entre los agentes hacen patente la manera en que mediante esas atribuciones la policía precisó una particular idea del orden. ${ }^{28}$ En las décadas precedentes la misma se ceñía al control de las prácticas criminales de igual modo que a los efectos de la confrontación partidaria, mientras que se extendía ahora sobre las ideas de la ampliación y transparencia electoral. En este marco, se intentó limitar la actividad de determinadas organizaciones, cuyas ideas acerca de la cuestión social eran interpretados como prédicas radicales que ponían en riesgo al orden establecido.

${ }^{27}$ AHSP, Órdenes del día, Talleres de Policía de la PBA, La Plata, 1912, T XX, n. 6835, 8 abr. 1912.

28 Por ejemplo, Memoria, p. 539-540. 
En una coyuntura signada por distintos procesos huelguísticos que asolaban la provincia, ${ }^{29}$ la policía condicionó el accionar del Partido Socialista, incorporado a la dinámica electoral, y relegó a las organizaciones anárquicas. Por una parte, se generaron puntos de contacto con su retórica en momentos en que la fuerza reclamaba mejores condiciones materiales y laborales. Con todo, el anarquismo fue soslayado en las elecciones, que continuaron siendo -junto a problemas del ámbito rural como el cuatrerismo- la principal preocupación para la policía. En la mirada policial el peligro anarquista no residía tanto en la propagación de sus ideas en los ámbitos culturales y políticos, sino en su potencial disruptivo sobre el orden social y el mundo del trabajo. La principal caracterización fue la del anarquismo como un sujeto colectivo con actitudes disolventes frente al orden garantido por el Estado y la constitución nacional y renuente al consenso social. El mayor desafío, por ende, refería a su ocupación física y simbólica del espacio público. Por lo que, como actor con potestad para la regulación de dicho espacio, la policía hizo uso de sus tecnologías y dependencias para disputar su intervención en las huelgas, al tiempo que negó numerosos pedidos de realizar actos públicos (BERARDI, 2018).

Aunque este control condicionaba el sentido de ampliación democrática del reformismo, la conducción policial intentó acatar y transmitir a sus subordinados las variantes prácticas electorales. Sin embargo, esas mismas disposiciones que ordenaban el sufragio sobre nuevas lógicas, evidencian que diversos comisarios se identificaban aún con la figura de Ugarte e intervenían a su favor. Se intercalan así los apercibimientos o las requisitorias para oficiales que cohesionaban a los votantes, "exigiéndoles la entrega de la libreta, para sufragar por el Partido Conservador". O que detenían a los partidarios del saenzpeñismo y del conservadurismo principista. ${ }^{30}$ Del mismo modo, en La Plata Rodolfo Moreno (h), una figura prominente de la fracción anti-ugartista, denunciaba la pervivencia de prácticas policiales que contrarrestaban la competencia abierta y democrática, que su grupo propugnaba. ${ }^{31}$

Es evidente que los proyectos reformistas moldearon las formas con que los actores policiales, sobre todo sus cúpulas, redefinieron su relación sobre la esfera de lo político. Ello no se tradujo, sin embargo, en que parte del personal subalterno modificara sus lealtades para con Ugarte y con Doyhenard. Desafío aún más significativo para el elenco

${ }^{29}$ Sobre las experiencias de politización y organización gremial tempranas en el ámbito bonaerense remitimos a Ansaldi (1993).

${ }^{30}$ Memoria, p. 572 y 566.

${ }^{31}$ Memoria, p. 573. 
gobernante que más allá de ajustarse a los cambios propuestos por el gobierno nacional con cierto éxito, no pudo cercenar completamente el poder de las viejas figuras conservadoras.

Frente a esas debilidades, Ugarte obtuvo un fuerte respaldo de la Legislatura para aprobar una ley Electoral que lo benefició (MELÓN PIRRO, 1994). De igual manera, el tejido del conservadurismo reposicionó fuertemente a Doyhenard. Las tramas relacionales desde su cargo en la Jefatura resultaron eficaces para que el gobernador Arias lo designara como Comisionado de La Plata a mediados de 1910. Mientras que también se afianzó dentro del partido, multiplicando sus redes en las comunas por su designación como vocal o presidente en los nuevos clubes y comités que se establecían.

Esta integración suponía una negociación de los sectores reformistas con aquellas figuras que representaban al viejo sistema caudillista con el que se había gobernado la provincia. Esas redes también fueron vehiculizadas en su tránsito como comisionado en la comuna platense, gracias a lo que solidificó su carrera política y redefinió su nombramiento en la policía. De hecho, Ugarte asumió de nuevo la gobernación de Buenos Aires en mayo de 1914, como candidato del Partido Conservador, que presidía desde fines de 1912. Convocó a Doyhenard para liderar la repartición policial, quien acentuaría las estrategias de su primera gestión.

\section{Conclusiones}

En este artículo examinamos una problemática poco transitada: las formas de intervención de la institución policial en la esfera política en la provincia de Buenos Aires a inicios del siglo XX. De hecho, las propias narrativas institucionales no incluyeron a la politización de las fuerzas, al tiempo que en algunos estudios históricos del período se destaca una suerte de naturalización acerca de la maleabilidad y control por parte de las elites dirigentes a la institución policial. Estas cuestiones han eclipsado el examen sobre el cariz y las formas concretas que nutrieron dicha dimensión política, que buscamos recuperar.

Así, problematizamos el protagonismo policía durante el "orden conservador", aportando complejidad a la actual revisitación historiográfica sobre el período. Abordamos la etapa 1902-1914 atendiendo a una subperiodización sensible a cómo se fue direccionando y modulando el proceso de articulación entre policía y política. Mostramos variantes acuerdos y tensiones en la intervención policial que fueron constitutivas de la política, a la vez que definitorias de la propia configuración institucional. Resulta difícil 
sintetizar los resultados obtenidos, ya que hemos privilegiado narrar con minuciosidad los clivajes, con la intención de mostrar a los diversos actores con sus intereses y estrategias en un contexto político convulsionado y cambiante. Pusimos la lente entonces las interacciones entre el poder ejecutivo provincial, las autoridades comunales, la Legislatura y las cúpulas y tropa policial.

Desde ya que no negamos que la policía asumió una activa participación en diversas manifestaciones públicas, principalmente en las instancias electorales, en tanto fue empleada como un elemento disciplinador ante posibles disidencias intra e interpartidarias. Pero matizamos la visión de la policía en tanto brazo ejecutor ya que señalamos que jefes, inspectores y agentes, leían las requisitorias de sus autoridades políticas en clave propia. La policía no actuaba ni se auto representaba como un actor subordinado, sino que se definía por sus cualidades profesionales y formas políticas adecuadas a las exigencias de las coyunturas.

Revelamos, en este sentido, que el proceso de fragmentación del tejido político y policial que había tenido lugar antes de 1902 fue revirtiéndose sobre una nueva convergencia entre las elites políticas y las cúpulas policiales, que encontró en la dupla Ugarte y Doyhenard su máxima correspondencia. Se fue (re)configurando un entramado de solidaridades dentro del tejido policial que, desde diferentes experiencias locales como la de Patagones, fueron afianzando las correspondencias con el conservadurismo. El detallado examen de este caso nos permitió advertir, con todo, la necesidad permanente de negociar la obediencia, que se tradujo en relaciones cambiantes que tuvieron también puntos de divergencia entre Doyhenard y el poder ejecutivo, así como con sus subordinados. Lo que tensiona la caracterización de un orden político hegemónico y de una policía jerarquizada y heterónoma. Igualmente, reveló otra modalidad política, en tanto la policía fue artífice de la construcción de fuerzas partidarias.

Mientras que entre 1906 y 1914, los cambios propiciados por la legislación electoral fueron modificando la articulación de los actores policiales con respecto a su intervención en los comicios y en la regulación de la esfera pública en un marco de abierta competencia de las fuerzas partidarias. Destacándose la adaptación a los requerimientos que exigía la ampliación del sufragio, en sus acciones electorales y también en el establecimiento de instancias pedagógicas de la fuerza. Así como en el control de actores considerados por fuera de la noción de orden que la institución configuró, como los ácratas, con quienes disputó el uso del espacio público, limitando su intervención gracias a sus potestades y dependencias. 
La transparencia electoral fue, por ende, un vector por el que el elenco gobernante y las Jefaturas pos Doyhenard intentaron legitimarse, pero no se pudo cercenar el poder de las viejas figuras conservadoras. Tras la experiencia reformista, Doyhenard ensayaría bajo una nueva gobernación de Ugarte la acentuación de los marcos identitarios y la modernización policial mediante una densa red de espionaje, que objetivó el control político sobre adversarios y el unanimismo conservador hasta 1916.

\section{Referências}

ALONSO, Paula. Jardines secretos, legitimaciones públicas: el Partido Autonomista Nacional y la política argentina de fines del siglo XIX. Buenos Aires: Edhasa, 2010.

ANSALDI, Waldo (Comp.). Conflictos-rurales pampeanos, 1900 1937. Buenos Aires: CEAL,1993.

BARRY, Viviana. Aproximaciones a los estudios de Policía en perspectiva histórica. Balance de un campo de estudios en expansión. Estudios Sociales del Estado, Buenos Aires, v. 4, n. 7, p. 1-16, 2018. Disponible en: http://hdl.handle.net/2133/16166. Acceso en: 12 abr. 2021.

BARTOLUCCI, Mónica; TARONCHER, Miguel. Cambios y continuidades en las prácticas político-electorales en la provincia de Buenos Aires: 1913-1922. In: DEVOTO, Fernando; FERRARI, Marcela (Comp). La construcción de las democracias rioplatenses: proyectos institucionales y prácticas políticas, 1900-1930. Buenos Aires: Biblos, 1994. p. 181-83.

BÉJAR, María Dolores. El régimen fraudulento: la política en la provincia de Buenos Aires, 1930-1943. Buenos Aires: Siglo XXI, 2005.

BERARDI, Pedro. De decorosos humanitarios a sectarios sediciosos: figuraciones sobre el anarquismo en las narrativas policiales (Buenos Aires, 1901-1917). In: NIETO, Agustín; VIDELA, Oscar (Comp.). El anarquismo después del anarquismo: una historia espectral. Mar del Plata: GESMAR Grupos de Estudios Sociales y Marítimos, 2018. p. 1-49.

BERARDI, Pedro. Viene á hacer de la policía uno de los resortes de esa máquina: la intervención del cuerpo policial bonaerense en la construcción del 'orden conservador', 1880-1902. Coordenadas, Rio Cuarto, n. 1, p. 162-187, 2019a. Disponible en: http://ppct.caicyt.gov.ar/index.php/coordenadas/article/view/14019/pdf. Acceso en: 22 abr. 2021.

BERARDI, Pedro. La intervención policial en la construcción del territorio fronterizo de la provincia de Buenos Aires, 1881-1912. Revista de Estudios Marítimos y Sociales, Mar del Plata, n. 15, p. 39-67, 2019b. Disponible en: https://estudiosmaritimossociales.org/rems/rems15/berardi.pdf. Acceso en: 22 abr. 2021. 
BIBLIOTECA NACIONAL DE ESPAÑA. Hemeroteca Digital. Ejemplares del título: Caras y caretas (Buenos Aires). "Ardua pesquisa", Caras y Caretas, año 5, n. 201, 9 jul. 1902, p. 1.. Disponible

en: http://hemerotecadigital.bne.es/issue.vm?id=0004139011\&search=\&lang=es. Acceso en: 22 abr. 2021.

BOTANA, Natalio. El orden conservador: La política argentina entre 1880 y 1916 . Buenos Aires: Edhasa, 1977.

BUCICH ESCOBAR, Ismael. El coronel Julio S. Dantas: como militar, como funcionario, como político, 1846-1922: homenaje a su memoria en el primer aniversario de su muerte. Buenos Aires: Ferrari, 1923.

CARRASCO, Ángel. Lo que yo ví desde el 80: hombres y episodios de la transformación nacional. Buenos Aires: PROCMO, 1947.

CASTRO, Martín. El ocaso de la república oligárquica: poder, política y reforma electoral: 1898-1912. Buenos Aires: Edhasa, 2012.

CUCCHI, Laura; ROJKIND, Inés. Oligarquía, república y democracia: debates sobre la vida política en la Argentina del orden conservador. Investigaciones y Ensayos, Buenos Aires, n. 65, p. 29-34, jul./dic. 2017. Disponible en: https://www.iye.anh.org.ar/index.php/iye/article/view/185/168. Acceso en: 12 abr. 2021.

FERNÁNDEZ IRUSTA, Pablo. Los conservadores bonaerenses y la reforma de la ley electoral provincial (1910-1913). Boletín del Instituto de Historia Argentina y Americana "Dr. Emilio Ravignani", Buenos Aires, n. 31, p. 79-122, 2009. Disponible en: http://www.scielo.org.ar/pdf/bihaar/n31/n31a03.pdf. Acceso en: 15 abr. 2021.

GALEANO, Diego; KAMINSKY, Gregorio (Coord.). Mirada (de) uniforme: historia y crítica de la razón policial. Buenos Aires: Teseo, 2011.

HORA, Roy. Autonomistas, radicales y mitristas: el orden oligárquico en la provincia de Buenos Aires (1880-1912). Boletín del Instituto de Historia Argentina y Americana "Dr. Emilio Ravignani", Buenos Aires, n. 23, p. 39-77, 2001. Disponible en: http://ravignanidigital.com.ar/_bol_ravig/n23/n23a02.pdf. Acceso en: 14 abr. 2021.

HORA, Roy. La política bonaerense: del orden oligárquico al imperio del fraude. In: PALACIO, Juan Manuel (Dir.). Historia de la Provincia de Buenos Aires: de la federalización de Buenos Aires al advenimiento del peronismo: 1880-1943. Buenos Aires: Edhasa, 2013. p. 51-81.

MELÓN PIRRO, Julio. La Ley Sáenz Peña de Ugarte, o el éxito de la reforma conservadora en la provincia de Buenos Aires. In: DEVOTO, Fernando; FERRARI, Marcela (Comp.). La construcción de las democracias rioplatenses: proyectos institucionales y prácticas políticas, 1900-1930. Buenos Aires: Biblos, 1994. p. 107-135.

MÍGUEZ, Eduardo. Gestación, auge y crisis del orden político oligárquico en la Argentina: balance de la historiografía reciente. PolHIs, Buenos Aires, año 5, n. 9, p. 38-68, 2012. Disponible: http://www.historiapolitica.com/datos/boletin/Polhis9_MIGUEZ.pdf. Acceso en: 25 abr. 2021. 
MUÑIZ, Diógenes; FORS, Luis; GAMBIER, Agustín. La policía de la provincia de Buenos Aires: su historia, su organización, sus servicios. La Plata: TIO, 1911.

PALACIO, Juan Manuel. Historia de la Provincia de Buenos Aires: de la federalización de Buenos Aires al advenimiento del peronismo: 1880-1943. Buenos Aires: Edhasa, 2013.

POLICÍA DE LA PROVINCIA DE BUENOS AIRES. Memoria Anual correspondiente al ejercicio 1911-1912. La Plata: Talleres de Joaquín Seré, 1912.

POLICÍA DE LA PROVINCIA DE BUENOS AIRES. Comisión Permanente de Investigaciones Históricas. Síntesis histórica de la Policía de la Provincia de Buenos Aires 1580-1980, La Plata: Policía de la Provincia de Buenos Aires, 1981.

ROMERO, Ana Leonor (Coord.). A treinta años de El orden conservador: un Dossier sobre un clásico de la historia política. Boletín Bibliográfico Electrónico del Programa Buenos Aires de Historia Política, Buenos Aires, año 1, n. 2, p. 7-12, 2008. Disponible en: http://historiapolitica.com/datos/boletin/dossier.pdf. Acceso en: 28 abr. 2021.

TATO, María Inés. Variaciones reformistas: los conservadores bonaerenses ante el desafío de la democratización, 1912-1919, Secuencia: Revista de Historia y Ciencias Sociales, México, $\mathrm{n}^{\circ}$ 63, p. 129-150, sept./dic. 2005. Disponible en: http://www.scielo.org.mx/pdf/secu/n63/2395-8464-secu-63-00128.pdf. Acceso en: 18 abr. 2021.

ZIMMERMANN, Eduardo. Los liberales reformistas: la cuestión social en Argentina 18901916. Buenos Aires: Sudamericana-UdeSA, 1995. 